\title{
Characterization of Thermally Regenerated Activated Carbons Used in Rum Production by Acoustic Emission Analysis, N2 and Ar Gas Adsorption
}

Harold Crespo Sariol' ${ }^{1}$, Thayset Mariño Peacok ${ }^{1}$ Jan Yperman ${ }^{2 *}$, Karen Leyssens ${ }^{3}$, Vera Meynen ${ }^{3}$, Angel Sanchez Roca ${ }^{4}$, Hipolito Carvajal Fals ${ }^{4}$, Ángel Brito Sauvanell ${ }^{1}$, Robert Carleer ${ }^{2}$ and Jose Navarro Campa ${ }^{5}$

${ }^{1}$ Chemical Engineering, Energetic Efficiency Center, Universidad de Oriente, Santiago de Cuba, Cuba

${ }^{2}$ Research Group of Applied and Analytical Chemistry, Hasselt University, Diepenbeek, Belgium

${ }^{3}$ Laboratory of Adsorption and Catalysis, University of Antwerp, Wilrijk, Belgium

${ }^{4}$ Mechanical Engineering, Universidad de Oriente, Santiago de Cuba, Cuba

${ }^{5}$ First Master of Cuban Rum, Cuba

\begin{abstract}
Acoustic emission analysis applied for the characterization of granular activated carbons (GAC) has been barely explored. The porosity of regenerated GAC used in rum production has been assessed using the acoustic emission method based on the signal envelope analysis by band-pass filtering at $1.3 \mathrm{kHz}$ of the sound produced by water flooding the activated carbon. Acoustic measurements have been correlated with porosity and surface area analysis applying argon at $87 \mathrm{~K}$ and $\mathrm{N}_{2}$ at $77 \mathrm{~K}$. The found relationship proves not only the almost equivalency but also the partly complementarity of both techniques and the possibility to determine the regeneration degree of GAC using the acoustic emission method.
\end{abstract}

Keywords: Activated carbon; Acoustic emission; Rum; Porosity; BET; Bubbles

\section{Introduction}

Activated Carbon (AC) adsorption is a common technique for eliminating various impurities in gas and liquid phase. AC (the most used industrial adsorbent) has been broadly and successfully applied in diverse industries such as: water treatment, production of chemicals, food processing, medical application, metallurgy or electronic devices because of its extended specific surface area, well-developed porous structure and superficial surface activated function [1,2]. AC can be used in a powdered or granular form $(0.2-5 \mathrm{~mm})$. In case of food processes, the activated carbons remove undesirable odors, colors, and unwanted components, improving its quality $[3,4]$. In spirits and liquor production such as the rum industry, granular activated carbon (GAC) is used to remove organic compounds that affect the sensorial quality of the final product [5]. For the rum refining process, fixed beds of GAC are placed in cylindrical contactors: "filters", where the primary rum to be refined (influent) flows through the carbon bed, and is withdrawn as "filtrated rum" (effluent) at the bottom of the column. When GAC become exhausted in the rum production, they are landfilled and replaced by fresh GAC. However, the landfilled GAC creates a solid waste problem. Therefore, regeneration seems essential for environmental, sustainable use of GAC adsorption technology and its techno-economic viability has to be established. For this reason the regeneration process of exhausted GAC in rum production should be applied and the effectiveness of regenerated GAC must be guaranteed. Among the regeneration procedures, thermal regeneration is considered as one of the most effective methods [6,7]. After the thermal regeneration process, the adsorption capacity of the GAC is efficiently restored due to the removal of the majority of adsorbed compounds. Four steps are usually involved in the thermal regeneration: (1) Drying (at temperatures of up to about $200^{\circ} \mathrm{C}$ ), (2) Thermal desorption (from about 200 to $500^{\circ} \mathrm{C}$ ), (3) Pyrolysis (at about 500 to $700^{\circ} \mathrm{C}$ ) and (4) Activation (at about $700^{\circ} \mathrm{C}$ and higher). The last process is performed in a steam or carbon dioxide atmosphere with $\mathrm{N}_{2}$ as carrier gas [6,7]. Each of these stages comprises several simultaneous steps and is associated with a particular temperature range and residence time in the reactor.
Therefore, due to the complexity of the processes and the variety in the composition of the adsorbed material (e.g., in rum production), it is not easy to find the optimum process conditions, in particular the optimum temperature and residence time combination. Problems may occur if the residence time in the reactor falls considerably below or exceeds the optimum time. If the regeneration is insufficient, the adsorbed material is not completely removed and the GAC adsorption capacity decreases. In case of over regeneration time, the micropore walls can be burned out to form meso and macro pores with the consequence that the adsorption capacity for larger molecules increases, but the adsorption capacity for small molecules decreases $[2,3,6,7]$ thus, affecting the quality of the rum.

In order to determine the GAC regeneration degree reached, a proper and fast analytical technique based on determination of apparent surface area and porosity has to be applied [8-10]. However, the technological facilities of rum producers are limited and thus the use of volumetric sorption equipment at cryogenic temperatures is not evident. Consequently, an alternative, economic, fast and reliable method to measure the regeneration degree reached for the GAC in rum production is needed. The use of acoustic measurements makes the control of the overall porosity and the porous structure of produced GAC possible [11-13]. Previously, the acoustic emission by water flooding the activated carbons used in the rum production process was studied; it was proven that the best measurements conditions were

*Corresponding authors: Jan Yperman, Research Group of Applied and Analytical Chemistry, Hasselt University, Diepenbeek, Belgium. Tel: 032-11-268320. Fax: 032-11-268301. E-mail: jan.yperman@uhasselt.be

Received June 19, 2017; Accepted July 07, 2017; Published July 09, 2017

Citation: Sariol HC, Peacok MM, Yperman J, Leyssens K, Meynen V, et al. (2017) Characterization of Thermally Regenerated Activated Carbons Used in Rum Production by Acoustic Emission Analysis, N2 and Ar Gas Adsorption. J Adv Chem Eng 7: 176. doi: 10.4172/2090-4568.1000176

Copyright: @ 2017 Sariol HC, et al. This is an open-access article distributed under the terms of the Creative Commons Attribution License, which permits unrestricted use, distribution, and reproduction in any medium, provided the original author and source are credited. 
obtained when the acoustic signal is processed at $1.3 \mathrm{kHz}$ [11-13]. Bubbles and its corresponding sound patterns are in general widely studied, theoretically analyzed and applied in many scientific fields. The analysis of acoustic and vibrating signals to characterize mechanical events such as pump cavitation, cavity effects in gas-jet impingement propellers and stir spot welding process have proven to be accurate and sensitive techniques [14-30].

This paper gives an improved approach of earlier findings [11-13], describing a new method for the characterization of activated carbons based on acoustic emission analysis. It results in a typical sound (acoustic) emission by bubbles moving through the bulk water and exploding at the liquid surface. The GAC sound is produced by the bubbles escaping from the GAC cracks and pores when water molecules displace the gas molecules occupying the air filled spaces inside of the GAC. The amount of produced bubbles is closely related to the porosity of the GAC $[11-13,31]$. However, the chemical and physical property of the probe liquid and the relationship with the GAC bubbling (acoustic) feature must be further studied. This correlation is not simple; liquids with similar physical properties (surface tension, density, polarity and viscosity) produce different bubbling patterns. The bubbling pattern of a GAC depends not only on the chemical-physical properties (or one individual property) of the used liquid but also on the chemicalphysical characteristics of the GAC surface [31]. The bubble volume fraction and rate at which the bubbles appear when approaching the water surface influence sound parameters as frequency and signal amplitude [11,13,14-18]. The acoustic emission produced in audible spectra can be analyzed by a proper acoustic signal analysis technique. In the case of GAC used in the rum production process, large amounts of organic compounds with different molecular sizes adsorb, and block cracks and pores of GAC, creating an important reduction of pore volume and specific surface area [11,13,30-32]. Exhausted GAC therefore result in a reduction of bubbling potential and consequently in a reduction and a change in the sound signal amplitude. If an efficient regeneration process is applied, the total volume of pores and the specific surface area of the GAC are recovered and consequently, the intensity of the acoustic signal produced by a regenerated GAC is higher than the exhausted GAC and comparable with the virgin GAC. Taking into account the detected differences in the parameters of the acoustic signals, the porous characteristics of exhausted, regenerated and virgin GAC can be evaluated.

In the current study, a comparison between the use of volumetric gas sorption and its deduced apparent BET surface area applying different gases and the acoustic emission technique is discussed in order to determine the porous characteristics of regenerated GAC under different conditions. The obtained results can be correlated with the GAC characteristics according to its regeneration degree. This work ratifies the practical benefits of using the acoustic technique to study porous characteristics of high-porous materials. The volumetric sorption techniques and its deduced apparent BET surface area confirmed the strength of the acoustic characterization method.

\section{Materials and Methods}

\section{Sample of exhausted GAC}

The exhausted sample of GAC $(0.8 \mathrm{~mm})$ to be regenerated was obtained from the major rum producer in Cuba based on the criteria of the rum taste experts (rum masters). A typical industrial fixed-bed rum filter previously declared as: "out of service" was used to take the most exhausted sample of GAC, located at the top of the GAC column according to technological characteristics of the rum filtration process $[13,31,32]$.

\section{Samples of regenerated GAC}

Six samples of GAC regenerated under different conditions were analyzed. Three of them were pre-treated by ammonia solution at $6.25 \mathrm{wt} \%$ before thermal regeneration in order to extract adsorbed compounds based on the reaction between ammonia and exhausted GAC [31,32]. The ammonia pre-treatment was applied to study the possibility of diminishing the severity of the thermal regeneration conditions by the extraction of adsorbed compounds prior regeneration. Thus, lower temperature and shorter residence time in the reactor could be demanded for GAC regeneration. According to this, the pre-treated regenerated GAC are termed as "PRAC" and the thermally regenerated GAC without previous ammonia treatment are designated as "TRAC". The virgin GAC was also analyzed to compare with the regenerated samples.

\section{Regeneration set-up}

The GAC regeneration experiments were performed in the setup depicted in Figure 1 consisted of the following: (1) Tubular quartz reactor; (2) Nabertherm horizontal oven; (3) Gas-flow meter with automatic valve; (4) Programmable FGH 1000 temperature controller (T.C.); (5) Programmable Schott TR 100 automatic burette; (6) PC.

Working description: Into the horizontal tubular quartz reactor $20 \mathrm{~g}$ of exhausted GAC sample is put and fixed in the center of the quartz tube using two glass wool gaskets. The quartz reactor is introduced into the horizontal oven. Once the oven and the reactor are prepared, a constant flow of nitrogen at $70 \mathrm{~mL} / \mathrm{min}$ is supplied by the gas-flow meter (3) to ensure an oxygen-deficient environment during the initial stages of the GAC regeneration process (drying and thermal desorption). Flushing $\mathrm{N}_{2}$, the oven is switch-on to heat the sample at a certain temperature with a predetermined heating rate previously programmed in the Programmable FGH 1000 temperature controller (4). Once the temperature for the third stage (pyrolysis) of the regeneration process has been reached, water is injected in the reactor with the $\mathrm{N}_{2}$ gas stream. Steam is produced, inducing a proper activation atmosphere for the GAC.

The steam flow rate of $1 \mathrm{~g}$ of water per gram of activated carbon was applied for the regeneration process of the exhausted carbon [6]. The heating rate was $5^{\circ} \mathrm{C} / \mathrm{min}$ to reach the programed activation temperature. Three combinations of regeneration temperature $(\mathrm{T})$ and residence time $(\mathrm{t})$ were explored for the PRAC- $(\mathrm{T} / \mathrm{t})$ and TRAC- $(\mathrm{T} / \mathrm{t})$ samples as follows:

\section{PRAC- $\left(450^{\circ} \mathrm{C} / 100 \mathrm{~min}\right)$}

PRAC- $\left(600^{\circ} \mathrm{C} / 80 \mathrm{~min}\right)$

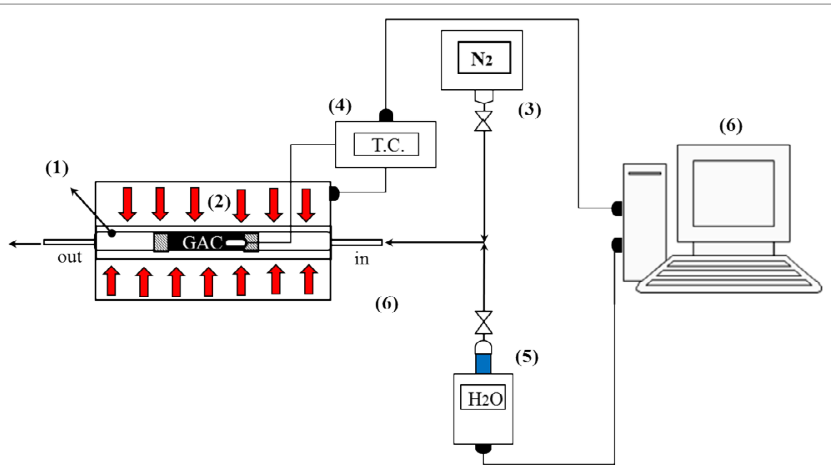

Figure 1: GAC regeneration set-up. 


\section{PRAC- $\left(800^{\circ} \mathrm{C} / 40 \mathrm{~min}\right)$}

TRAC- $\left(450^{\circ} \mathrm{C} / 100 \mathrm{~min}\right)$

TRAC- $\left(600^{\circ} \mathrm{C} / 80 \mathrm{~min}\right)$

\section{TRAC- $\left(800^{\circ} \mathrm{C} / 40 \mathrm{~min}\right)$}

Relatively low temperatures as $450^{\circ} \mathrm{C}$ and $600^{\circ} \mathrm{C}$ at long residence times were also explored in order to evaluate the regeneration progress.

\section{BET analysis and porous characteristics}

Different gases were used to assess the porous characteristics of the GAC. The porous structure of GAC was characterized by $\mathrm{N}_{2}$ adsorption at $77 \mathrm{~K}$ and $\mathrm{Ar}$ at $87 \mathrm{~K}$ using the Autosorb-iQS and the Autosorb 1 respectively. The choice of adsorptive is crucial in the characterization of porous materials. Nitrogen at $77 \mathrm{~K}$ has been widely used, but the interpretation of the isotherm data is not always straightforward. For various reasons, argon adsorption at $87 \mathrm{~K}$ is considered to be more reliable and is now recommended, particularly for micropore size analysis [10]. In our case, the regeneration process produces changes in the porous structures of the GAC, those changes must be evaluated. Therefore, applying both gases a more complete characterization is achieved and its correlation with the acoustic method can be proposed in better conditions, even defining the more representative adsorptive gas for the acoustic method. Although acoustic emission method and gas sorption analysis are performed under quite different conditions, the phenomenological correlation between both methods to assessing the porous characteristics of activated carbons can be deduced.

Before analysis, the sample was degassed $16 \mathrm{~h}$ at $300^{\circ} \mathrm{C}$ in vacuum. The apparent surface area $\left(\mathrm{S}_{\mathrm{BET}}\right)$ was estimated by the BET equation. The amount of gas adsorbed at the relative pressure of $p / p_{0}=0.96$ was employed to determine the volume of pores. The micropore volume $\left(\mathrm{V}_{\mathrm{DR}}\right)$ was calculated by applying the Dubinin-Radushkevich equation. The quenched-solid-density functional theory (QSDFT) and nonlocal-density functional theory (NLDFT) were used to determine the pore size distribution $[9,10]$.

\section{Acoustic emission experiments}

Acoustic emission set-up: The experiments were performed using the same sound enclosure box presented in [11,13]. A G.R.A.S. microphone, Type 46AG (Frequency range $3.15 \mathrm{~Hz}-20 \mathrm{kHz}$, Dynamic range $17 \mathrm{~dB}-146 \mathrm{~dB}$, Sensitivity $50 \mathrm{mV} / \mathrm{Pa}$ ) for precision acoustic measurements was used.

In contrast with the severe out gassing procedure to perform the volumetric gas adsorption described in $2.4\left(300^{\circ} \mathrm{C}\right.$, high vacuum, overnight), for the acoustic method the samples were just dried $3 \mathrm{~h}$ at $110^{\circ} \mathrm{C}$ using Boxun BGZ series oven applying ASTM Standard Test Methods for moisture determination in Activated Carbon [11,13,33]. Samples were refreshed in a silica-gel desiccator till being measured.

Signal capture and processing: Following the procedure presented in $[11,13]$, the GAC acoustic emission is captured by a microphone (placed into the sound enclosure box where the immersion of GAC takes place) (Figure 2), amplified and digitalized using a NI USB6211 data acquisition card. Digital data was PC recorded and being processed using MATLAB $^{\circ}$ software. The set-up was calibrated using a G.R.A.S.42AP Intelligent Piston phone. The recording time for the GAC sound was $90 \mathrm{~s}$ for all the samples.

The methodology applied for signal processing and analysis was performed following a similar methodology described in $[13,28]$. Briefly; to discard any external interference associated with the frequency of interest, spectrogram and components of frequency within the range of $1-1.6 \mathrm{kHz}$ were recorded at empty sound enclosure box. No external interferences (noise) were found in the original signal in the selected frequency range. The selected cut-off frequency of the band-pass (BP) filter was $1.3 \mathrm{kHz}$. Once the signal component in the frequency range of interest was extracted, a characterization of the acoustical signals within the time domain using the Hilbert Transform of the vibro-acoustical signals was possible. The Hilbert Transform of the function $\mathrm{x}(\mathrm{t})$ is defined by the equation (1) [28].

$$
H(x)=\frac{1}{\pi} \int_{-\infty}^{\infty} \frac{x(t)}{x-t} d t
$$

The Hilbert transform facilitates the formation of the analytical signal, which is useful for BP signal processing and could be correlated with GAC porous characteristics which can define its regeneration degree [13].

\section{Results and Discussion}

Figure 3 presents the $\mathrm{N}_{2}$ sorption isotherms of the samples. The isotherms for all carbons are type I with a hysteresis loop type $\mathbf{H 4}$ according to IUPAC classification [10], indicating a microporous nature of adsorbents. The hysteresis loops for the regenerated samples are similar and broader than the GAC-virgin loop. This behavior can be more associated with the filling of micropores than with capillary condensation in mesopores according to the value of the " $\mathrm{C}$ " BET constant related to the energy of monolayer adsorption depicted in Table 1 .

Figure 4 presents the sorption isotherms of the samples using argon at $87 \mathrm{~K}$ as gas probe. In concordance with $\mathrm{N}_{2}$ results, the isotherms for all carbons are type I with a hysteresis loop type $\mathbf{H} \mathbf{4}$ according to IUPAC classification [10], confirming the microporous nature of adsorbents. However, the followed pattern by the volumes adsorbed and the extent of the isotherms is somewhat different from the $\mathrm{N}_{2}$ results.

As it was reported by IUPAC [10], argon at $87 \mathrm{~K}$ is more suitable

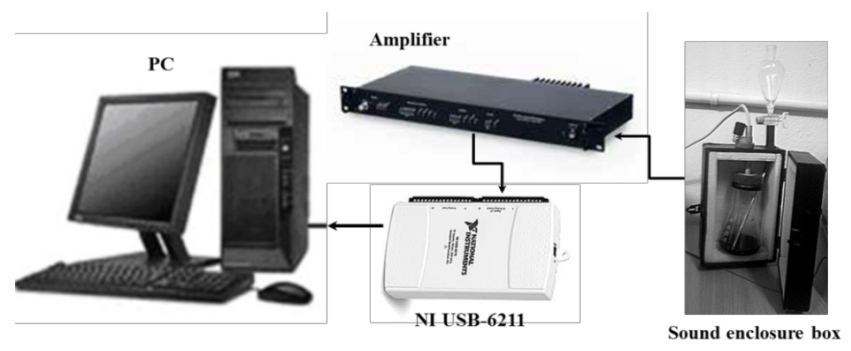

Figure 2: Scheme of the experimental set-up for acoustic emission analysis.

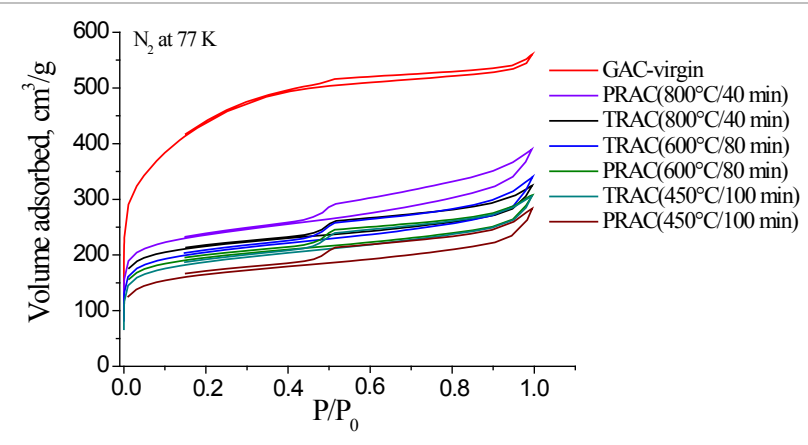

Figure 3: $\mathrm{N}_{2}$ sorption isotherms at $77 \mathrm{~K}$ of $\mathrm{GAC}$. 


\begin{tabular}{|c|c|c|c|c|c|c|c|}
\hline \multirow[t]{2}{*}{ Samples } & \multirow[t]{2}{*}{$\begin{array}{l}\text { Pore } \\
\text { Shape }\end{array}$} & \multicolumn{2}{|c|}{$\begin{array}{c}\text { "Apparent" } \\
\mathbf{S}_{\text {BET }} \\
\mathbf{m}^{2} / \mathbf{g}\end{array}$} & \multicolumn{2}{|c|}{$C$} & \multicolumn{2}{|c|}{$\begin{array}{c}\text { Micropore } \\
\text { Volume }\left(V_{D R}\right) \\
\mathbf{c m}^{3} / \mathbf{g}\end{array}$} \\
\hline & & $\mathbf{N}_{2}$ & Ar & $\mathrm{N}_{2}$ & $\mathrm{Ar}$ & $\mathrm{N}_{2}$ & $\mathrm{Ar}$ \\
\hline PRAC- $\left(450^{\circ} \mathrm{C} / 100 \mathrm{~min}\right)$ & Slit & 614 & 601 & 680 & 383 & 0.26 & 0.25 \\
\hline PRAC- $\left(600^{\circ} \mathrm{C} / 80 \mathrm{~min}\right)$ & Slit & 730 & 713 & 1150 & 554 & 0.31 & 0.28 \\
\hline PRAC- $\left(800^{\circ} \mathrm{C} / 40 \mathrm{~min}\right)$ & Slit & 878 & 918 & 1976 & 524 & 0.37 & 0.37 \\
\hline TRAC- $\left(450^{\circ} \mathrm{C} / 100 \mathrm{~min}\right)$ & Slit & 694 & 655 & 1266 & 373 & 0.30 & 0.27 \\
\hline TRAC- $\left(600^{\circ} \mathrm{C} / 80 \mathrm{~min}\right)$ & Slit & 761 & 824 & 1590 & 663 & 0.32 & 0.34 \\
\hline TRAC- $\left(800^{\circ} \mathrm{C} / 40 \mathrm{~min}\right)$ & Slit & 810 & 912 & 1701 & 539 & 0.34 & 0.37 \\
\hline GAC-virgin & Slit & 1573 & 1644 & 191 & 114 & 0.67 & 0.56 \\
\hline
\end{tabular}

Table 1: Characterization of porous structure of activated carbons using $\mathrm{N}_{2}(77 \mathrm{~K})$ and $\operatorname{Ar}(87 \mathrm{~K})$ sorption.

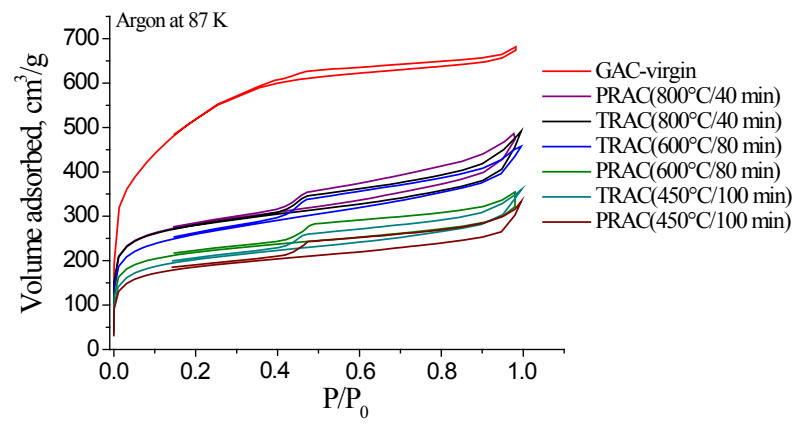

Figure 4: Ar sorption isotherms at $87 \mathrm{~K}$ of GAC.

probe gas than $\mathrm{N}_{2}$ at $77 \mathrm{~K}$ as in contrast to nitrogen, which has a quadrupolar moment; argon does not interact with the surface functional groups. Argon at $87 \mathrm{~K}$ provides more reliable results than $\mathrm{N}_{2}$ for the porous characterization in high porosity microporous materials [10]. This will be discussed later in more detail.

Table 1 displays the porous structure of the six GAC samples using $\mathrm{N}_{2}$ and $\mathrm{Ar}$ as probe gases. For GAC-virgin, the highest apparent surface area is measured and is around 1570 and $1640 \mathrm{~m}^{2} / \mathrm{g}$ for nitrogen and argon respectively. The apparent $\mathrm{BET}$ area of the regenerated carbons follows a growing trend according to the regeneration temperature applied. However, based on gas sorption results, the GAC-virgin apparent surface area is almost two times larger than the TRAC and PRAC $-\left(800^{\circ} \mathrm{C} / 40 \mathrm{~min}\right)$ which are the explored regenerated samples with the higher BET apparent surface area. Comparing the porous structure between TRAC and PRAC the porous characteristics are quite similar.

When assessing the porosity data, temperature ratifies to be the most determining parameter to obtain higher regeneration degrees. According to $\mathrm{N}_{2}$ and Ar sorption, the treatment with ammonia of the exhausted GAC prior to the regeneration produces has only a minor effect over the regeneration degree reached. All the samples have the same pore shape. The micropore volume of the regenerated samples is comparable, being approximately half of the GAC virgin micropore volume.

The "C" BET constant is quite different between regenerated and virgin samples suggesting a higher energy of interaction for the regenerated samples (between 3 and 10, and between 3 and 6 times higher than in GAC virgin in the case of $\mathrm{N}_{2}$ and Ar correspondently). As argon has more accessibility to the carbon pores with no specific interaction between the adsorbed molecules at $87 \mathrm{~K}$ and the surface functional groups, the results are different in comparison with $\mathrm{N}_{2}$ sorption analysis [10]. In the case of $\mathrm{N}_{2}$, a systematic increase in " $\mathrm{C}$ " value can be noticed for PRAC and TRAC samples. In the case of Ar each time the " $600^{\circ} \mathrm{C} / 80$ min" samples show the highest " $\mathrm{C}$ " value. The C-value for Ar is lower in comparison with $\mathrm{N}_{2}$ results, not only considering the magnitude of the constant but also in the differences observed between regenerated and virgin GAC, coinciding with the absence of a quadrupolar moment in Ar, limiting specific interactions with the surface. Nevertheless, the " $C$ " values for all the regenerated samples are high, indicating gas adsorption in narrow micropores [10]. Although significant differences between the regenerated and the virgin GAC in terms of specific surface area and volume of pores are noticeable, results are more descriptive using Ar as probe gas. In this case, a systematic increment in the specific surface area, volume of pores and pore width is observed in correspondence with the regeneration temperature.

Figure $5 \mathrm{a}$ and $5 \mathrm{~b}$ presents the pore size distribution in the carbon samples according to NLDFT and QSDFT respectively and slit shaped pores as model. Based on QSDFT and NLDFT theories, the pore width is ranging between super-micro and micropores respectively. In general, the pores have comparable sizes. GAC virgin has larger pores than the other samples and much more porosity based on $\mathrm{N}$ sorption. In this case, clearly two maxima are found: one around 0.7 $\mathrm{nm}$ (QSDFT) and $1.2 \mathrm{~nm}$ (NLDFT) and a broader second one around 1-2 nm (QSDFT) and 1.7-2.7 nm (NLDFT).

Additionally, the first peak is broader compared to the regenerated samples located at the same region. The pore sizes between 1.2 and $3 \mathrm{~nm}$ are clearly lesser present for TRAC and PRAC with different regeneration level pointing to preferential adsorption of organic compounds in the pores with a size within this range. According to

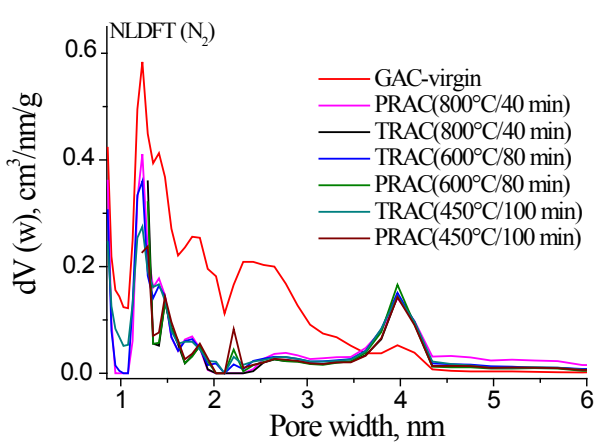

(a)

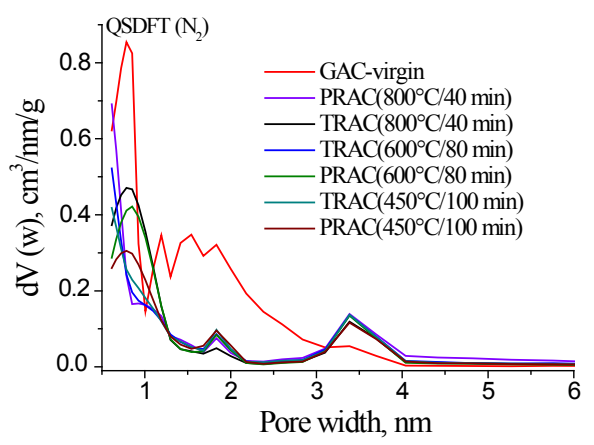

(b)

Figure 5: Pore size distribution determined by NLDFT (a) and QSDFT (b) methods using $\mathrm{N}_{2}$ at $77 \mathrm{~K}$. 
[6] and considering the types of adsorbed compounds found in the exhausted GAC in rum production reported in recent researches $[13,31]$, this could be caused by pyrolyzed depositing of carbonaceous residue [6]. The pore size distributions of the regenerated samples are quite similar, indicating the presence of larger porosity visible as slit shaped pores and the appearance of a broader second peak in the range of 3-4 $\mathrm{nm}$ (QSDFT) and $4 \mathrm{~nm}$ (NLDFT). In acoustic emission experiments, the wider distribution of pores in the virgin GAC can be translated in a sustained higher bubble production with stronger sound amplitude than other regenerated samples [11,13].

In the case of pore size distribution based on Ar sorption presented in Figure $6 a$ and $6 b$, results are comparable with the $N_{2}$ pore size assessment. The first peak around $0.7 \mathrm{~nm}$ (QSDFT) and $1.2 \mathrm{~nm}$ (NLDFT) are confirmed. However, a broader region between 0.7-3 nm (NLDFT) and 1.2-2 nm (QSDFT) is larger for the GAC-virgin than the regenerated samples.

According the NLDFT and QSDFT pore-models, for $\mathrm{N}_{2}$ a systematic increase in specific surface and micropore volume can be observed, but rather a decrease in pore width can be seen for the PRAC samples and an increase for the TRAC samples. The effect of the ammonia pre-treatment over the regeneration degree reached based on these observations is not that obvious. Pore width values for $\mathrm{Ar}$ are consistent with the regeneration process and comparable between NLDFT and QSDFT methods leading to more homogeneous results. GAC-virgin presents wider pores than regenerated carbons according to $\mathrm{Ar}$, but not to $\mathrm{N}_{2}$.

According to the gas sorption results, the significant effect of the applied temperature on the restoration of the porous characteristics in the regenerated GAC is confirmed. Based on $\mathrm{Ar}$, at $450^{\circ} \mathrm{C}$ the recovering

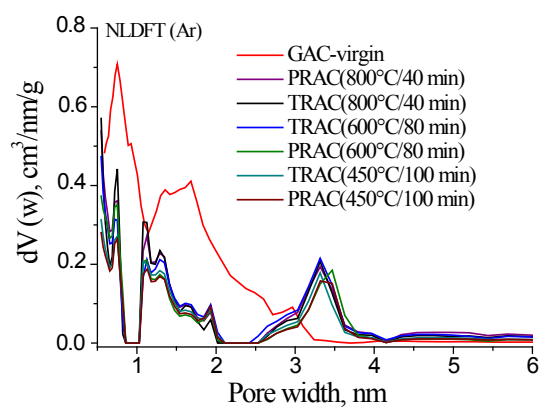

(a)

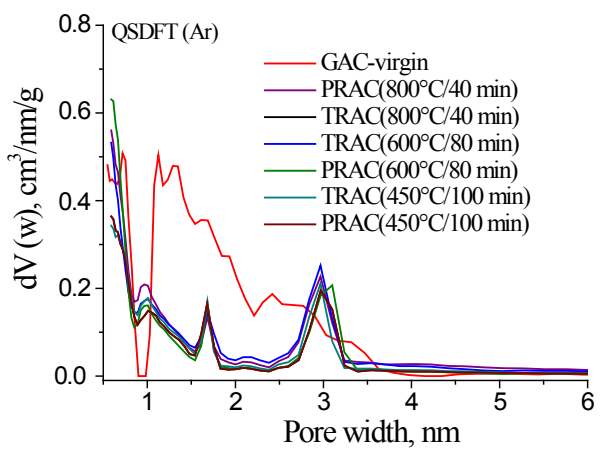

(b)

Figure 6: Pore size distribution determined by NLDFT (a) and QSDFT (b) methods using $\mathrm{Ar}$ at $87 \mathrm{~K}$. of apparent $\mathrm{S}_{\mathrm{BET}}$ area and $\mathrm{V}_{\mathrm{DR}}$ represents about 40 and $46 \%$ respectively from the original parameters in the virgin GAC. In contrast, at $800^{\circ} \mathrm{C}$ the restoration of the porous characteristics is around $53 \%$ for apparent $\mathrm{S}_{\mathrm{BET}}$ area and $66 \%$ for $\mathrm{V}_{\mathrm{DR}}$. Similar values can be obtained from $\mathrm{N}_{2}$ results. This suggests in the case of the GAC regeneration in rum production, the process must be performed at temperatures at least at $800^{\circ} \mathrm{C}$ and probably higher than $800^{\circ} \mathrm{C}$ to obtain larger apparent surface area and volume of pores closer to the virgin material. A more effective removal of pyrolytic residues could be possible if regeneration were conducted over $800^{\circ} \mathrm{C}$ for the regeneration of GAC loaded with organic compounds which can produce carbonaceous residues [6].

Using acoustic measurements a frequency spectrum comparison between the GAC-virgin and the regenerated carbon (TRAC and PRAC) at the most extreme regeneration condition $\left(800^{\circ} \mathrm{C} / 40 \mathrm{~min}\right)$ was first performed.

Figure 7 shows the RMS, spectrograms and frequency component distribution of the GAC acoustic signal for the regenerated GAC (TRAC- $\left.\left(800^{\circ} \mathrm{C} / 40 \mathrm{~min}\right)\right)$ and $\mathrm{GAC}$-virgin.

Comparing the RMS between regenerated and virgin GAC (Figure $7 \mathrm{a}$ and $7 \mathrm{~d}$ ) some slight differences between the samples can be seen. The signal power produced by GAC-virgin is more intense than regenerated GAC. However, the RMS of the TRAC- $\left(800^{\circ} \mathrm{C} / 40 \mathrm{~min}\right)$ acoustic signal is clearly higher than the RMS of an exhausted GAC (Figure 1Supplementary), giving an initial evidence of the increment of activity for the regenerated sample. In contrast, the spectrograms depicted in Figure $7 \mathrm{~b}$ and $7 \mathrm{e}$ present very similar features in terms of frequency distribution with a wide range of observed frequency components due to the resonator nature of the exploding bubbles $[11,13,26,29]$. The same frequency component around $1-1.5 \mathrm{kHz}$ and its harmonics can be observed in exhausted, regenerated and GACvirgin samples but with different intensities (arrows in Figure $7 \mathrm{~b}$ and $7 \mathrm{e})$. The GAC-virgin sound is the most intense; as it is expected for a virgin adsorbent. The regenerated and virgin condition of each sample can be noticed just by direct comparison between spectrograms.

Figure $7 \mathrm{c}$ and $7 \mathrm{f}$ show the magnification of the spectral range with the peak of interest in the regenerated and GAC-virgin sound signal respectively. The same frequency components distribution featured by a peak in the frequency domain around $1.3 \mathrm{kHz}$ was found [13]. Comparing the amplitude of the dominant frequency peaks in the case of regenerated and GAC-virgin, similar values can be observed, which is in line with the regenerated condition of TRAC- $\left(800^{\circ} \mathrm{C} / 40 \mathrm{~min}\right)$. Both regenerated and GAC-virgin presented a clearly higher intensity than the intensity of the frequency peak at $1.3 \mathrm{kHz}$ for the exhausted GAC (Figure 1 Supplementary). Additionally, PRAC- $\left(800^{\circ} \mathrm{C} / 40 \mathrm{~min}\right)$ was also analyzed, showing a very similar feature of RMS, spectrogram and frequency component distribution (Figure 2 Supplementary) in comparison with TRAC- $\left(800^{\circ} \mathrm{C} / 40 \mathrm{~min}\right)$.

Figure $8 \mathrm{a}$ and $8 \mathrm{~b}$ show the acoustic signal envelopes of TRAC and PRAC samples filtered at $1.3 \mathrm{kHz}$ respectively, also including in both figures the exhausted and virgin GAC signal envelopes. According to Figure $8 \mathrm{a}$ and $8 \mathrm{~b}$, all the explored samples present a multi-peak pattern in the signal envelopes. The virgin GAC is the most complex one. First a shoulder around 5-6 s on the first main multi peak around 9-13 s, with again a shoulder at $1.4 \mathrm{~s}$ can be noticed. A second peak can be observed around $16 \mathrm{~s}$, followed by a broad third one centered at $23 \mathrm{~s}$ and a fourth weak one at $34 \mathrm{~s}$, referring to a very variated porous structure. According to the multi-peak pattern for the regenerated samples, a main initial peak (around 5-7 s) is obtained with high amplitude in comparison with the other peaks (except for TRAC- $\left(450^{\circ} \mathrm{C} / 100 \mathrm{~min}\right)$ 


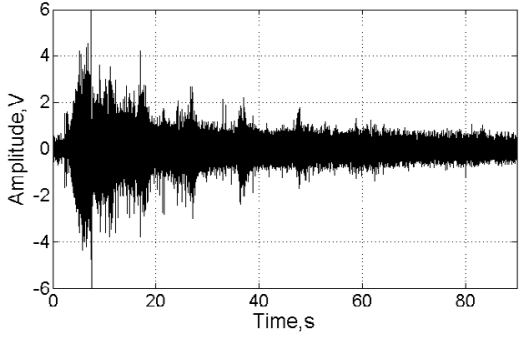

(a)

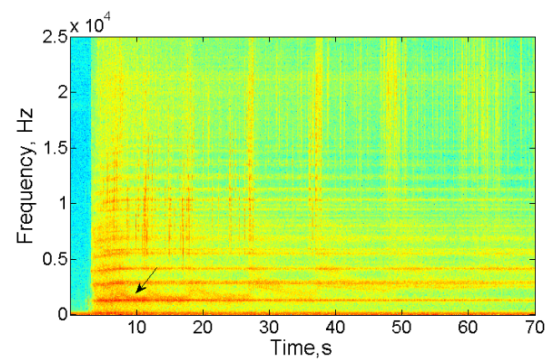

(b)

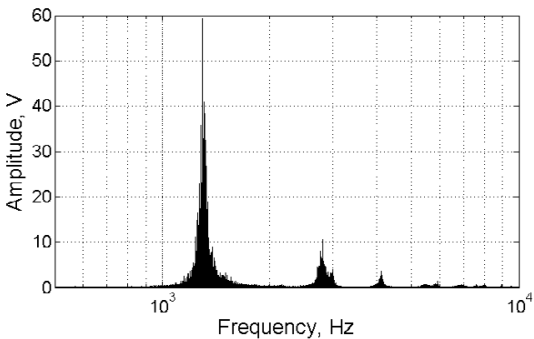

(c)

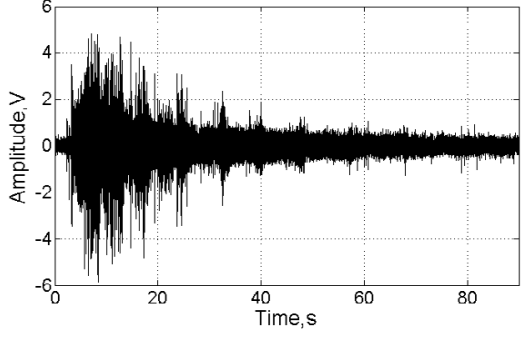

(d)

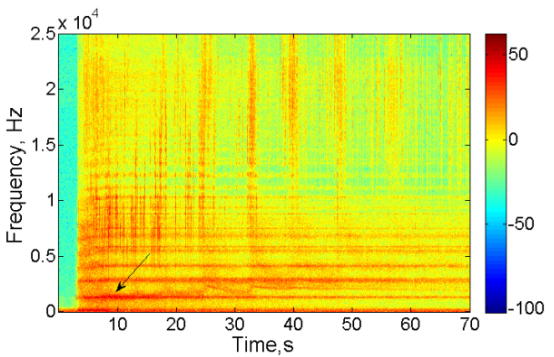

(e)

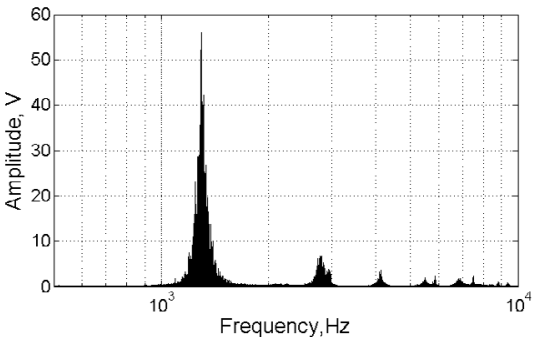

(f)

Figure 7: RMS of the GAC acoustic signal: (a) TRAC- $\left(800^{\circ} \mathrm{C} / 40 \mathrm{~min}\right)$ and (d) GAC-virgin, spectrograms: (b) TRAC-( $\left.800^{\circ} \mathrm{C} / 40 \mathrm{~min}\right)$ and (e) GAC-virgin and frequency component distribution: (c) TRAC- $\left(800^{\circ} \mathrm{C} / 40 \mathrm{~min}\right)$ and (f) $\mathrm{GAC}$-virgin.

and TRAC- $\left(800^{\circ} \mathrm{C} / 40 \mathrm{~min}\right)$, a shoulder is also noticed at $\left.3-4 \mathrm{~s}\right)$; this main peak is associated with the first water - GAC contact. The air is massively released from the GAC pores. It is a sudden and intense process. For TRAC samples, this pattern is rather more diverse than in the case of the PRAC samples, pointing to differences in its porous characteristics.

Comparing the pattern of the exhausted GAC with the regenerated and virgin GAC, further great differences can be noticed. The shape of the pattern and the time space where the main peak is observed for the exhausted GAC gives the first evidence of sensibility for detecting differences in the porous characteristics between the GAC samples. After this first broad and less intense peak (around $10 \mathrm{~s}$, with a small preceding shoulder at 5-7 s), the amplitude decays by a rather monotonic slow decreasing amplitude at a function of time. According to Figure $8 \mathrm{a}$ and $8 \mathrm{~b}$, all peak characteristics depends on the regeneration conditions, the higher the temperature and the residence time applied, the higher the amplitude of the registered peaks are. The air released from the GAC pores are related to these peak features.

Differences in the envelope shape and signal amplitude are noticeable between samples. Regenerated TRAC (Figure 8a) and PRAC (Figure 8b) present a main peak sharper than GAC virgin which is broader (still bubbling for longer) and displaced in time. A relationship between the regeneration temperature and the main peak amplitude can be observed. The higher the regeneration temperature is, the higher the main peak. During thermal regeneration the porous structure and pore size distribution of the GAC change [6], opening new and wider pores and cracks giving to water an easier access to the more internal porosity (micro and mesopores) The pore widening process enhances the fast removal of the air in form of bubbles from the internal pores which in turn creates a sound signal with higher amplitude. This fast filling process of the small pores (via wider pores) produces a fast increasing and decreasing signal amplitude with high slope. Although with apparently different phenomenological nature, actually, the results of both methods: acoustic emission and the volumetric sorption analysis are linked with each other, being partly confirmative and partly complementary. The volumetric sorption analysis indicates a narrowing process at micro-pore scale; in contrast, the acoustic signal indicates a pore widening process occurring at the same time. An evidence of this phenomenon is presented in Figures $5 a, 5 b, 6 a$ and $6 b$ where a peak for pores distribution around 3-4 $\mathrm{nm}$ in the regenerated samples was detected. Undetectable by BET analysis, but visible in a change in the hysteresis loop, wider pores (e.g., macro-pores), slits, cracks as a product of structural damage during regeneration could be present in a larger distribution in regenerated than in virgin GAC $[6,10]$.

It is a well-known fact that in activated carbons the micro and 

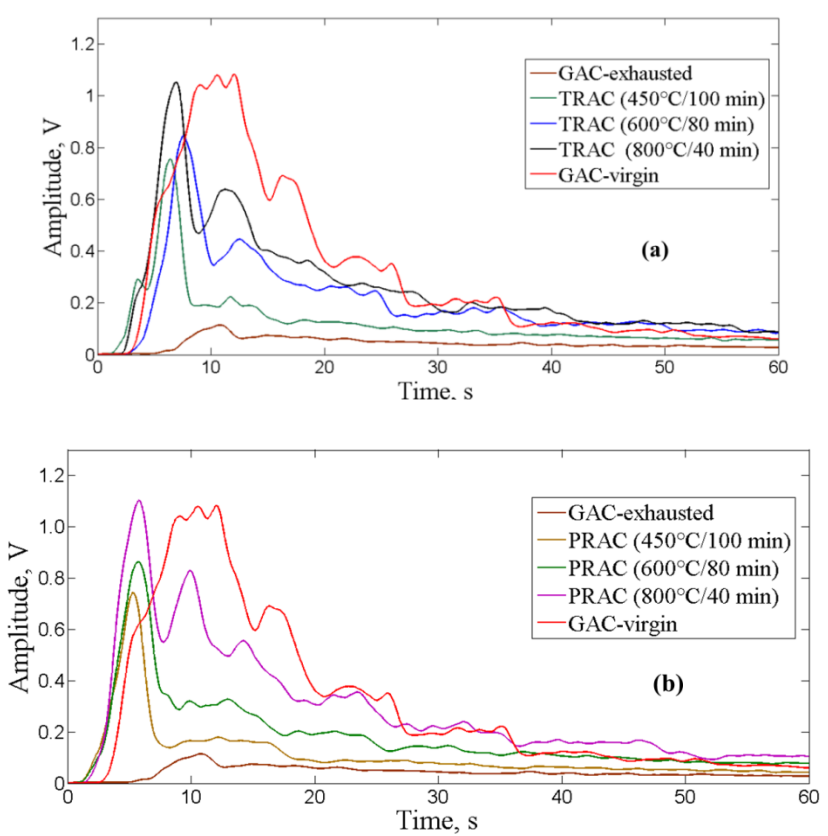

Figure 8: Signal envelopes of TRAC (a) and PRAC (b) samples (filtered at $1.3 \mathrm{kHz})$.

mesoporosity represents practically the total pore volume and the largest total apparent surface area. In contrast, macropores are of less importance for the adsorption process in activated carbons. Their contribution to the surface area and pore volume is rather small. However, macropores enable adsorbate molecules to pass rapidly to smaller pores situated deeper within the particles of active carbons and being primarily relevant for the mass transfer into the interior of the adsorbent particles [2,8-10].

Based on the GAC porous characteristics described above, we can accept that the volume of air displaced by the flooding water and the thereby produced sound in the acoustic emission method is mainly coming from the micro and mesoporous structure of the carbon. As the macropores do not significantly contribute to the total volume of pores in the GAC, their direct contribution to the acoustic signal amplitude can be neglected in the acoustic emission method. Nevertheless, the GAC macro porosity plays an important role in defining the pattern of the acoustic signal envelope. Regarding the importance of GAC macro porosity to give water an easier access to smaller pores and thereby enhancing the mass transfer process, the volume of air in bubbles form coming from the macro and mesopores finds a fast way out from the carbon particle using the macropores, slits and cracks. Therefore producing a massive release of bubbles consequently with an acoustic signal of high intensity which abruptly drops after the air is completely removed due to micro and mesopores water filling. Concluding, the general feature of the acoustic signal envelope according to the porous characteristics of the GAC can be summarized in the following types of correlations:

Type I: GAC with high micro porosity and macro porosity: A broad main peak of high amplitude followed by a systematic decreasing trend, featured by secondary peaks of comparable amplitude. The larger the volume of micropores, the broader is the signal peak.

Type II: GAC with high micro porosity and low macro porosity: A broad main peak of moderate amplitude and delayed in time scale followed by a smooth decreasing trend slope, featured by secondary peaks of comparable signal intensity which are gradually attenuated.

Type III: GAC with low micro porosity and high macro porosity: A sudden and sharp main peak of very high amplitude followed by an abrupt decreasing trend, featured by fewer secondary peaks of low amplitude. The lower the volume of micropores, the shorter is the initial main peak

Type IV: GAC with low micro porosity and macro porosity: A broad main peak of very low amplitude and delayed in time scale followed by a smooth decreasing trend slope without significant secondary peaks.

Although quite similar, the signal envelopes behavior of PRAC and TRAC samples regenerated at the same conditions of temperature and residence time are slightly different. At relative low regeneration temperature $\left(450-600^{\circ} \mathrm{C}\right)$, the main and second peaks for TRAC (Figure 8a) are higher in amplitude and broader in time domain than PRAC (Figure 8b). Possibly, the reaction between the ammonia and adsorbed compounds on the GAC (mainly phenolics compounds $[31,32])$ modifies these compounds producing new ones which could be less volatile, thus not being efficiently desorbed at this temperature range, keeping part of the pores blocked or/and maybe producing more carbonaceous residues which are more difficult to eliminate than the residues formed by the original compounds. Therefore, a broader and higher second peak for PRAC is indicating a better regeneration of internal porosity trending to type I signal envelope pattern. At $800^{\circ} \mathrm{C}$, the behavior of the envelope curves for TRAC and PRAC follow different patterns. In this case, the main and second peaks of PRAC are higher than TRAC peaks. The difference is more noticeable if the second peaks are compared. As the intensity of the peak amplitude can be associated to the accessibility to the pores with a consequent massive air releasing in form of bubbles, We can accept that at $800^{\circ} \mathrm{C}$ the new compounds formed during the ammonia pre-treatment in PRAC were removed from the pores but creating a widening process in the original GAC porous structure at macro scale. In contrast, analyzing the behavior of the TRAC envelope curve at $800^{\circ} \mathrm{C}$, the main and second peaks are also delayed in time scale in comparison with PRAC peaks, indicating less accessibility to the internal pores. Furthermore, the second peak for TRAC is broader than the PRAC peak which has more abrupt slope. That phenomenon could be attributable to the less porosity at macro scale for the TRAC (less damage to the porous structure) and/or possible carbonaceous residues not totally eliminated.

The main peak of the exhausted GAC can give us evidences that relate the main peak with the water accessibility to the internal porosity (pattern type IV), the main peak slope of the GAC exhausted is not so high, the water takes more time to get access to inner pores to remove the air as adsorbed organics compounds or its carbonaceous residues are blocking and narrowing the majority of the pores. As the GAC virgin has not been regenerated, keeping its original integrity, the signal intensity is higher than the one of the regenerated samples with a broader main peak, because of loss in and less accessible pore structures describing a type I pattern.

Taking into account the second peak amplitude; differences between regenerated samples are more noticeable. According to this, the second peak can be interpreted as the formation of "internal" and less accessible (narrow) porosity in the material, at $800^{\circ} \mathrm{C}$ (TRAC and PRAC $\left.-\left(800^{\circ} \mathrm{C} / 40 \mathrm{~min}\right)\right)$ the regeneration was better than at $450^{\circ} \mathrm{C}$ (TRAC and PRAC- $\left(450^{\circ} \mathrm{C} / 100 \mathrm{~min}\right)$ which described a type III pattern) more available pores were formed. In the case of GAC virgin, the main peak is sharing the same time-space scale of the second peak 
for regenerated samples PRAC and TRAC, it can be assumed that GAC virgin has more internal pores present. In regenerated samples, a visible third peak is only found for regenerated at $800^{\circ} \mathrm{C}$.

Based on gas adsorption and acoustic emission analyses the regenerated GAC samples are structurally different from the virgin GAC and exhausted GAC samples. The regeneration process produces changes in the GAC grain and in its porous structure. From one side; carbonaceous residues of adsorbed organic compounds found in rum production (e.g., aromatic, polyphenols and lignin) $[4,5,10,13]$ lead to narrowing meso and micropores; while the thermal treatment under steam-oxidizing environment produces structural damages in the GAC particles, opening wider pores (at macro scale), slits and cracks in the regenerated carbons [6].

Table 2 displays the values of the total integral area under the signal envelope curves of Figure 8 (sound surface: SS [13]) for the regenerated GAC samples. Five independent regenerations were performed and the material was mixed to create one homogeneous sample.

Each regenerated-mixed sample was acoustically measured in five independent experiments. A normal distribution for the acoustic emission results was confirmed. The averaged value of the SS for each sample is presented in Table 2. The Multiple Comparison Method was applied to determine statistical differences between the mean of the samples. The applied method was the Fisher's Lower Significant Difference (LSD) method. Based on statistical analysis, significant differences were found between the SS of regenerated GAC in terms of the regeneration temperature applied.

The area under the envelope curve "integral" (sound surface (SS) expressed in V.s, see Figure $8 \mathrm{a}$ and $8 \mathrm{~b}$ was used as parameter to correlate with the gas sorption characterization. The integral area under the envelope curve (SS) can give information about the amount and total rate of produced bubbles and its volume. Thus, it provides information about the bubble potential produced by GAC during the whole bubbling process in time domain. As these air bubbles are formed by air escaping from the GAC pores (mainly from meso and micropores), then SS value can be correlated with the volume of pores of granular activated carbons [11]. In Figure $9 a$ and $9 b$, the correlations between $\mathrm{V}_{\mathrm{DR}}$ and $\mathrm{S}_{\mathrm{BET}}$ with $\mathrm{SS}$ are depicted for both gases.

According to the plots presented in Figure 9, satisfactory non-linear correlation between SS and the porous structure parameters of GAC can be proposed. In both cases ( $\mathrm{Ar}$ and $\mathrm{N}_{2}$ ) an increasing polynomial or exponential models can be fitted in order to estimate the apparent $\mathrm{S}_{\mathrm{BET}}$ surface and $\mathrm{V}_{\mathrm{DR}}$ based on acoustic measurements. The non-linear correlation found between methods is not unexpected considering that the acoustic phenomenon obeys a logarithmic function.

$$
y=y_{0}+A \cdot e^{-\left(\frac{x}{t}\right)}
$$

Table 3 displays the parameters and characteristics of experimental

\begin{tabular}{|c|c|c|}
\hline Samples & SS (in V.s) & $\boldsymbol{\sigma}$ (SS) (in V.s) \\
\hline PRAC- $\left(450^{\circ} \mathrm{C} / 100 \mathrm{~min}\right)$ & 9.21 & \pm 0.2 \\
\hline TRAC- $\left(450^{\circ} \mathrm{C} / 100 \mathrm{~min}\right)$ & 9.25 & \pm 0.5 \\
\hline PRAC- $\left(600^{\circ} \mathrm{C} / 80 \mathrm{~min}\right)$ & 14.04 & \pm 0.5 \\
\hline TRAC- $\left(600^{\circ} \mathrm{C} / 80 \mathrm{~min}\right)$ & 15.32 & \pm 0.9 \\
\hline $\mathrm{TRAC}^{\circ}\left(800^{\circ} \mathrm{C} / 40 \mathrm{~min}\right)$ & 18.23 & \pm 1.1 \\
\hline PRAC- $\left(800^{\circ} \mathrm{C} / 40 \mathrm{~min}\right)$ & 18.74 & \pm 0.9 \\
\hline GAC-virgin & 24.01 & \pm 1.3 \\
\hline
\end{tabular}

Table 2: SS values of the GAC signal envelope. data fitted at exponential growth (eq. 2). Comparing the values of correlation coefficients between $\mathrm{N}_{2}$ and Ar; similar values are obtained. However, by a comparative inspection on the plots presented in Figure 9, based on the sequential trajectory and the distribution of the data points, a more sensitive correlation for Ar can be noticed, especially in the case of $V_{D R}$. The abrupt change in the curve slope (Figure 9a) in the section between 18 and $24 \mathrm{Vs}$ for $\mathrm{N}_{2}$ with a correspondent 0.67 $\mathrm{cm}^{3} / \mathrm{g}$ laying separately from the other data points is less noticeable in the case of Ar. The abrupt change in the tail of the curve makes a less linear correlation between the parameters of both methods visible, being difficult to estimate porous characteristics in this zone as a small increment in the SS value, represents an important change in the volume of pores and the apparent surface area. In contrast, the found correlation with $\mathrm{Ar}$ is rather smooth in terms of the data distribution, being a less abrupt change in the curve tail, thus, more suitable to predict porous characteristics in this zone than $\mathrm{N}_{2}$, also confirmed by its better regression coefficients. This plot behavior suggests that the suitability of argon at $87 \mathrm{~K}$ as probe gas correlates somewhat superior with the acoustic emission method than $\mathrm{N}_{2}$ at $77 \mathrm{~K}$.

According to both results, the order in the regeneration (activation) degree in the explored samples can be proposed as follows:

GAC-Virgin $>$ PRAC $-\left(800^{\circ} \mathrm{C} / 40 \mathrm{~min}\right) \approx>\mathrm{TRAC}-\left(800^{\circ} \mathrm{C} / 40\right.$ $\min )>\mathrm{TRAC}-\left(600^{\circ} \mathrm{C} / 80 \mathrm{~min}\right) \approx>\mathrm{PRAC}-\left(600^{\circ} \mathrm{C} / 80 \mathrm{~min}\right)>\mathrm{TRAC}-$ $\left(450^{\circ} \mathrm{C} / 100 \mathrm{~min}\right) \approx>\operatorname{PRAC}-\left(450^{\circ} \mathrm{C} / 100 \mathrm{~min}\right)$.

\section{Conclusions}

It can be stated that the acoustic technique based on signal processing of sound produced by GAC flooded with water is a

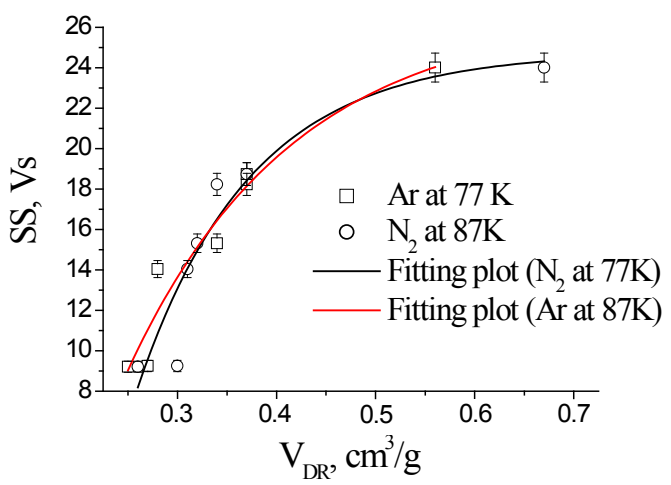

(a)

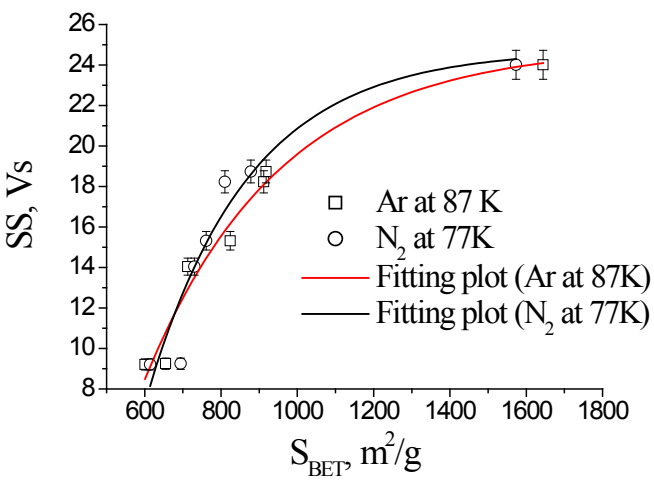

(b)

Figure 9: Correlation between the porous characteristics of GAC and the sound surface SS of signal envelopes filtered at $1.3 \mathrm{kHz}$. 


\begin{tabular}{|c|c|c|c|c|c|c|c|c|}
\hline Gas & & $\mathbf{y}_{\mathbf{0}}$ & error $\left(\mathbf{y}_{\mathbf{0}}\right)$ & $\mathbf{A}$ & Error $(\mathbf{A})$ & $\mathbf{t}$ & Error (t) & $\mathbf{R}^{\mathbf{2}}$ \\
\hline \multirow{2}{*}{$\mathbf{A r}$} & $\mathbf{V}_{\mathrm{DR}}\left(\mathrm{cm}^{3} / \mathrm{g}\right)$ & 26.8 & \pm 4.0 & -79.5 & \pm 8.4 & 0.17 & $\pm 7 \cdot 10^{-3}$ & 0.946 \\
\cline { 2 - 11 } & $\mathbf{S}_{\text {BET }}\left(\mathrm{m}^{2} / \mathrm{g}\right)$ & 25.0 & \pm 1.6 & -89.0 & \pm 31.8 & 356.4 & \pm 84 & 0.967 \\
\hline \multirow{2}{*}{$\mathbf{N}_{2}$} & $\mathbf{V}_{\mathrm{DR}}\left(\mathrm{cm}^{3} / \mathrm{g}\right)$ & 24.8 & \pm 2.7 & -160.3 & \pm 14.2 & 0.11 & $\pm 5 \cdot 10^{-3}$ & 0.889 \\
\cline { 2 - 11 } & $\mathbf{S}_{\text {BET }}\left(\mathrm{m}^{2} / \mathrm{g}\right)$ & 24.7 & \pm 2.0 & -167.7 & \pm 12.7 & 265.4 & \pm 89.0 & 0.922 \\
\hline
\end{tabular}

Table 3: Parameters and characteristics of experimental data fitted at exponential growing (first order).

sensitive method for determining porous characteristics of granular activated carbons, specifically for assessing the regeneration degree of granular activated carbons used in the rum production process. It is demonstrated that the integral area under the curve of the GAC sound signal envelope (SS) in the time domain obtained by BP filtering at 1.3 $\mathrm{kHz}$ can be satisfactory correlated with $\mathrm{BET}$ and $\mathrm{V}_{\mathrm{DR}}$ results using $\mathrm{N}_{2}$ and Ar as probe gases, although not linearly.

The regeneration process of exhausted GAC used in rum production modifies the porous structure of the material. A pore narrowing process apparently by pyrolytic residues deposition and the formation of wider pores by structural damage taking place at the same time during the regeneration process. No significant effect of ammonia pre-treatment over the regeneration degree was found based on volumetric gas sorption experiments. However, visible differences were detected based on the acoustic method, pointing at the ammonia pre-treatment could lead to the GAC porous structure deterioration due to a widening process of the pores, mainly if the regeneration is conducted at $800^{\circ} \mathrm{C}$ or higher temperature.

It was confirmed that the porous characteristics in the regenerated GAC is highly dependent on the applied temperature. The higher the temperature, the larger is the apparent surface area and volume of pores obtained. However, at $800^{\circ} \mathrm{C}$ the reestablishment of these porous parameters just reaches about $50-55 \%$ in comparison with the virgin material, possibly because of insufficient removal of pyrolytic residues as rum is a complex mixture of organic compounds such as polyphenols which produce important amounts of carbonaceous residues. In that case, higher temperatures should be explored to evaluate if better results can be obtained.

The simplicity and advantages of the acoustic emission method can be very interesting as a complementary analytical technique to characterize high-porosity materials. Acoustic emission methods can be satisfactory applied to study saturated GAC with organic compounds, which is not possible in case of volumetric gas adsorption (nitrogen, argon or others) due to the necessary degassing in the sample preparation.

\section{Acknowledgements}

The authors would like to thank VLIR-UOS project between Belgium and Cuba for providing funding and granting the support of the current and future studies.

\section{References}

1. Hsieh CT, Teng HZ (2000) Influence of mesopore volume and adsorbate size on adsorption capacities of activated carbons in aqueous solutions. Carbon 38: $863-869$

2. Worch E, de Gruyter W (2012) Adsorption Technology in Water Treatment $\mathrm{GmbH} \&$ Co., pp: 25-268

3. Roop CB, Meenakshi G (2005) Activated Carbon Adsorption. Taylor and Francis Group, Boca Raton, Florida, United States, pp: 414-415.

4. Maarse H (2010) Volatile compounds in foods and beverages. TNO-CIVO Food Anal Inst Zeist, Netherlands, pp: 261-387.

5. Queris HO (2007) Science and technologies of distillates beverages. Research Institute to Food Industry of Cuba, Cuba, pp: 11-19.

6. Van VM (1991) The regeneration of activated carbon. J S Afr Inst Min Metal
91: $59-67$

7. Xue H, Hongfei L, Ying Z (2014) Regeneration methods to restore carbon adsorptive capacity of dibenzothiophene and neutral nitrogen hetero aromatic compounds. Chemical Engineering Journal 243: 315-325.

8. Neimark AV, Lin Y, Ravikovitch PI, Thommes M (2009) Quenched solid density functional theory and pore size analysis of micro-mesoporous carbons. Carbon 47: 1617-1628.

9. Stoeckli F, Daguerre E, Guillot A (1999) The development of micropore volumes and widths during physical activation of various precursors. Carbon 37: 2075-2077

10. Matthias T, Katsumi K, Neimark AV, Olivier JP, Rodriguez-Reinoso F, et al (2015) Physisorption of gases, with special reference to the evaluation of surface area and pore size distribution (IUPAC Technical Report), IUPAC \& De Gruyter, Pure Appl Chem.

11. Crespo SH, Yperman J, Brito SA, Carleer R, Navarro CJ, et al. (2016) Nove acoustic approach for the characterization of granular activated carbons used in the rum production. Ultrasonic 70: 53-63.

12. Crespo SH (2015) Procedimento para obtener el espectrosonoro de carbones activados granulares. Cuban Office of Industrial Property (OCPI), Official bulletin No: 325, Patent International Classification, p: 132.

13. Crespo SH, Marino PT, Yperman J, Sanchez RA, Carvajal FH, et al. (2017) Comparative study between acoustic emission analysis and immersion bubblemetric technique, TGA and TD-GC/MS in view of the characterization of granular activated carbons used in the rum production. Beverages 3: 1-21.

14. Fedorchenko Al, Chernov AA (2003) Exact solution of the problem of gas segregation in the process of crystallization. International Journal of Heat and Mass Transfer 46: 915-919.

15. Terrill EJ, Melville KW (2000) A broadband acoustic technique for measuring bubble size distributions: laboratory and shallow water measurements Journal of Atmospheric and Oceanic Technology 17: 220-239.

16. Gilbert JB, Howea MS, Koch RM (2012) On sound generated by gas-jet impingement on a bubbly gas-water interface, with application to supercavity self-noise. Journal of Sound and Vibration 331: 4438-4447.

17. Commander KW, Prosperetti A (1989) Linear pressure waves in bubbly liquids: comparison between theory and experiments. Journal of the Acoustical Society of America 85: 732-746.

18. Havlickova MM (1997) The Cocoa Sound Effect-Audible Rising of the Tone Pitch. Prague, Private Communications.

19. Tabacchi M, Asensio C, Pavon I, Recuero M, Mir J, et al. (2013) A statistical pattern recognition approach for the classification of cooking stages the boiling water. Applied Acoustics 74: 1022-1032.

20. Manasseh R, Yoshida S, Rudman M (1998) Bubble formation processes and bubble acoustic signals. Third International Conference on Multiphase Flow, Lyon, France.

21. Nikolovska A, Manasseh R, Ooi A (2003) Visualizing the acoustic field around bubbles using a hydrophone-scanning method. The Seventh Asian Symposium on Visualization, Singapore.

22. Vazquez A, Sanchez RM, Salinas-Rodriguez E, Soria A, Manasseh R (2005) A glance at three measurement techniques for bubble size determination Experimental Thermal and Fluid Science 30: 49-57.

23. Doney GD (1994) Acoustic Boiling Detection. Dept of Nuclear, Engineering, Massachusetts Institute of Technology, USA.

24. Batchelor GK (1969) Compression waves in a suspension of gas bubbles in liquid. Fluid Dynamics Transactions 4: 425-445.

25. Foley AW, Howe MS, Brungart B (2010) TA Spectrum of the sound produced by a jet-impinging on the gas-water interface of a supercavity. Journal of Sound and Vibration 329: 415-424. 
Citation: Sariol HC, Peacok MM, Yperman J, Leyssens K, Meynen V, et al. (2017) Characterization of Thermally Regenerated Activated Carbons Used in Rum Production by Acoustic Emission Analysis, N2 and Ar Gas Adsorption. J Adv Chem Eng 7: 176. doi: 10.4172/2090-4568.1000176

Page 10 of 10

26. Mirko CC, Jurij PP (2009) Detection of cavitation in operation of kinetic pumps. Use of discrete frequency tone in audible spectra. Applied Acoustics 70: 540-546.

27. Fernandez JB, Roca AS, Fals HC, Macias EJ, De la Parte MP (2012) Application of vibroacoustic signals to evaluate tools profile changes in friction stir welding on AA 1050 H24 alloy. Sci Technol Weld Join 17: 501-510.

28. Macias EJ, Roca AS, Fals HC, Muroand JCS, Fernández JB, et al. (2015) Characterisation of friction stir spot welding process based on envelope analysis of vibro-acoustical signals. Sci Technol Weld Join 20: 172-180.

29. Travnıcek Z, Fedorchenko Al, Pavelka M, Hruby J (2012) Visualization of the hot chocolate sound effect by spectrograms. Institute of Thermomechanics, VVI Academy of Sciences of the Czech Republic, Prague 8, Czech Republic. Journal of Sound and Vibration 331: 5387-5392.
30. Crespo SH, Marino PT, Yperman J, Sauvanell BA, Carleer C, et al. (2015) Characterization of granularactivated carbons used in the rum production by immersion "bubblemetric technique" in a pure liquid. J Food Process Beverages 4: $1-10$

31. Crespo SH, Maggen J, Czech J, Reekmans G, Reggers G (2017) Characterization of the exhaustion profile of activated carbon in industrial rum "filters" based on TGA, colorimetry and NMR relaxometry. Materials Today Communication 11: 1-10.

32. Crespo SH, Vanreppelen K Yperman J, Brito SA Carleer R (2016) A colorimetric method for the determination of the exhaustion level of granular activated carbons used in the rum production. Beverages 2: 1-19.

33. ASTM (2011) Standard Test Methods for Moisture in Activated Carbon, D 2867-04. ASTM International: West Conshohocken, PA, USA. 